\title{
Marqibo $^{\circledR}$ (vincristine sulfate liposome injection) improves the pharmacokinetics and pharmacodynamics of vincristine
}

\author{
Jeffrey A. Silverman $\cdot$ Steven R. Deitcher
}

Received: 15 October 2012/ Accepted: 22 November 2012/Published online: 5 December 2012

(C) The Author(s) 2012. This article is published with open access at Springerlink.com

\begin{abstract}
Vincristine (VCR) is a mainstay of treatment of hematologic malignancies and solid tumors due to its welldefined mechanism of action, demonstrated anticancer activity and its ability to be combined with other agents. VCR is an M-phase cell cycle-specific anticancer drug with activity that is concentration and exposure duration dependent. The pharmacokinetic profile of standard VCR is described by a biexponential elimination pattern with a very fast initial distribution half-life followed by a longer elimination half-life. VCR also has a large volume of distribution, suggesting diffuse distribution and tissue binding. These properties may limit optimal drug exposure and delivery to target tissues as well as clinical utility as a single agent or as an effective component of multi-agent regimens. Vincristine sulfate liposome injection (VSLI), Marqibo ${ }^{\circledR}$, is a sphingomyelin and cholesterol-based nanoparticle formulation of VCR that was designed to overcome the dosing and pharmacokinetic limitations of standard VCR. VSLI was developed to increase the circulation time, optimize delivery to target tissues and facilitate dose intensification without increasing toxicity. In xenograft studies in mice, VSLI had a higher maximum tolerated dose, superior antitumor activity and delivered higher amounts of active drug to target tissues compared to standard VCR. VSLI recently received accelerated FDA approval for use in adults with advanced, relapsed and refractory Philadelphia chromosome-negative ALL and is in development for untreated adult ALL, pediatric ALL and untreated aggressive NHL. Here, we summarize the nonclinical data for VSLI that support its continued clinical development and recent approval for use in adult ALL.
\end{abstract}

J. A. Silverman $(\bowtie) \cdot$ S. R. Deitcher

Talon Therapeutics Inc., 400 Oyster Point Blvd, Suite 200,

South San Francisco, CA 94080, USA

e-mail: jsilverman@talontx.com
Keywords Liposome $\cdot$ Marqibo $\cdot$ Pharmacokinetics · Vincristine $\cdot$ VSLI $\cdot$ Xenograft

\section{Introduction}

Introduced over 45 years ago, vincristine (VCR) remains a potent and widely used anticancer agent, particularly for childhood and adult hematologic malignancies and solid tumors including sarcomas. However, sub-optimal pharmacokinetic properties and dose-related neurotoxicity prevent realization of the full potential of this agent. VSLI (vincristine sulfate liposome injection, $0.16 \mathrm{mg} / \mathrm{mL}$ (Marqibo $\left.{ }^{\circledR}\right)$ ) is a novel formulation of VCR that encapsulates the drug in sphingomyelin and cholesterol nanoparticles. The VSLI liposome is distinct from alternate liposomes used in other approved pharmaceutical products and is uniquely suited to contain, deliver, and dose intensify VCR. Here, we review the nonclinical investigations which demonstrate VSLI's optimized pharmacokinetic profile, enhanced drug delivery to target cancer tissues and increased activity in tumor models. These and other nonclinical studies supported the clinical development of VSLI which led to the recent approval of VSLI by the US FDA for treatment of adult patients with Philadelphia chromosome-negative ( $\mathrm{Ph}-$ ) acute lymphoblastic leukemia (ALL) in second or greater relapse or whose disease has progressed following two or more antileukemia therapies.

\section{Vincristine background}

VCR was initially discovered in a screening program investigating the potential antidiabetic properties of extracts from the widely cultivated white- or pink-flowered 
periwinkle plant, Cantharanthus roseus (formerly known as Vinca rosea Linn) [1-3]. Although ineffective as an oral antidiabetic treatment, the periwinkle extract was found to potently inhibit leukocyte production and maturation. Significant antileukemia activity of the alkaline fractions in animal models led to the subsequent isolation of several alkaloids, most potently from the leaves, which include the compounds now known as vincristine, vinblastine, vinleurosine and vinrosidine.

VCR is a highly active cell cycle-dependent anticancer drug. Extensive research on the mechanism of action of VCR has demonstrated that it binds to tubulin causing microtubule depolymerization, metaphase arrest and apoptotic death of cells undergoing mitosis $[4,5]$. Tubulin is essential for the normal polymerization of mitotic spindle microtubules. VCR binding to spindle microtubules alters spindle structure and function in a concentrationdependent manner. At low concentrations, VCR stabilizes the spindle apparatus which prevents chromosome segregation and results in metaphase arrest and inhibition of mitosis. At higher concentrations, disruption and total depolymerization of microtubules has been observed. The effect of short-term VCR exposure on mitotic arrest is reversible and cells can proceed normally through the cell cycle if the drug is removed. In contrast, long-term exposure to high concentrations of VCR results in lethal cytotoxicity [6-10]. Thus, the antitumor potency of VCR is dependent on the concentration and duration of exposure and the number of cells transiting through mitosis during the period of drug exposure. Interference of microtubule function also disrupts other cellular processes that involve microtubules, such as intracellular transport and cellular organization $[4,11,12]$. As a result of its interruption of microtubule function, especially evident during M-phase, cells accumulate in metaphase contributing to VCRinduced cytotoxicity $[11,13]$.

VCR-mediated antitumor activity may also include antivascular and antiangiogenic properties. In vitro, VCR inhibits the secretion of angiogenic factors such as vasculature endothelial growth factor (VEGF) by normal and drug-resistant human tumor cells [14], inhibits the proliferative activity and formation of capillary networks in cultured endothelial cell assays, and reduces the migratory activity of tumor cells in Matrigel assays [15]. In mouse models, VCR and other vinca alkaloids decrease vascular flow in tumors and normal tissues [16-19]. Antiangiogenic activity and decreased microvasculature density in tumor xenograft models have been described following VCR therapy [20]. The role of microtubules in these effects has not been established.

After clinical trials demonstrated anticancer activity in humans, the US FDA granted marketing approval for VCR in 1963. It has subsequently become an essential component of multi-drug chemotherapeutic regimens for the treatment of hematologic malignancies [21]. Early demonstration of VCR's activity and dose-response relationship in acute leukemia and Hodgkin's lymphoma led to clinical investigations in additional cancers [1]. Standard VCR has subsequently been approved for use in many neoplasms, including ALL, and in combination with other agents for the treatment of Hodgkin's disease, non-Hodgkin's lymphoma (NHL), rhabdomyosarcoma, neuroblastoma and Wilms' tumor. The usual dose of VCR for adults is $1.4 \mathrm{mg} / \mathrm{m}^{2}$ administered intravenously once a week. However, the oncology community and most vincristine-containing cancer treatment regimens routinely limit individual standard vincristine doses to $2.0 \mathrm{mg}$ (i.e., dose capping) in an attempt to minimize neurotoxicity.

Despite its potent antineoplastic activity, however, VCR has several pharmacological limitations. VCR plasma pharmacokinetics are described by a bi-exponential profile with a very short and extensive distribution half-life followed by a longer elimination half-life (Fig. 1); the volume of distribution is large, suggesting wide and diffuse distribution and perhaps extensive tissue binding (Table 1). These pharmacological properties may limit its optimal clinical benefit by limiting plasma and cancer tissue $\mathrm{C}_{\max }$ and cancer tissue drug exposure.

\section{Liposome overview}

Liposomes are small phospholipid vesicles that are versatile drug carriers which can be used to overcome the potential barriers of many drugs and allow effective delivery to their target tissues such as tumors (reviewed in [22-27]). Liposomes are simple, self-assembling vesicles with either single phospholipid bilayers (unilamellar) or multiple phospholipid bilayers that enclose an aqueous core, which can include a therapeutic drug "payload". Liposomes can be used to solve sub-optimal pharmaceutical properties such as low solubility, instability and rapid metabolism; they can also alter the distribution of drugs and offer the potential of selective delivery to the site of action $[22,28]$. To be effective as a delivery system, liposomes balance stability and time in the systemic circulation with release, or bioavailability, of the drug at the target site. VCR exhibits low solubility in aqueous solutions at physiological $\mathrm{pH}$ in vitro and has a rapid initial plasma $\mathrm{Cl}$ and extensive volume of distribution in vivo (Fig. 1; Table 1) $[4,5,12,29]$. These physico-chemical and pharmacokinetic properties combined with VCR's narrow therapeutic index and strong anticancer activity make it well suited for liposome technology to improve its utility in cancer therapy. 


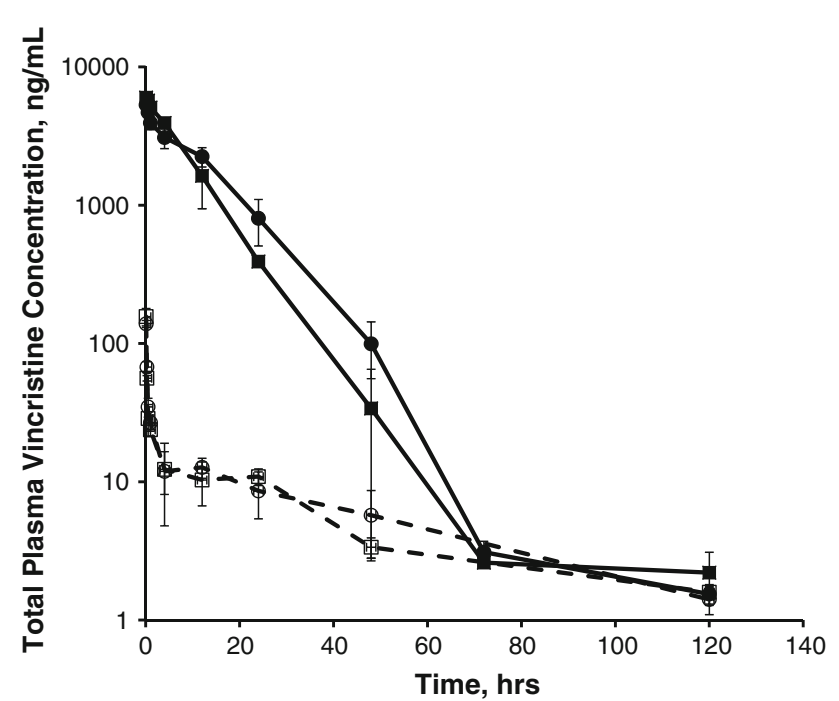

Fig. 1 Plasma vincristine concentration following administration of $2 \mathrm{mg} / \mathrm{m}^{2}$ of VCR (dashed lines) or VSLI (solid lines) to rats. Vincristine drug concentrations were measured in plasma from Sprague-Dawley rats $(N=3 / \mathrm{sex}$, except at $120 \mathrm{~h}, N=5)$ at the indicated timepoints post-dose of $2 \mathrm{mg} / \mathrm{m}^{2}$ VSLI (solid lines) or vincristine (dashed lines). Symbols indicate the following: Male VCR (open circle), Female VCR (open square), Male VSLI (filled circle), Female VSLI (filled square)

Table 1 Pharmacokinetic parameters in VSLI- and VCR-treated rats at $2.0 \mathrm{mg} / \mathrm{m}^{2}$

\begin{tabular}{lcccccr}
\hline Formulation & $\begin{array}{l}C_{\max } \\
(\mathrm{ng} / \mathrm{mL})\end{array}$ & $\begin{array}{l}\mathrm{AUC}_{\mathrm{inf}} \\
(\mathrm{ng} \cdot \mathrm{h} / \mathrm{mL})\end{array}$ & $\begin{array}{l}t_{1 / 2 \lambda 1} \\
(\mathrm{~h})\end{array}$ & $\begin{array}{l}t_{1 / 2 \lambda \mathrm{z}} \\
(\mathrm{h})\end{array}$ & $\begin{array}{l}\mathrm{Cl} \\
\left(\mathrm{mL} / \mathrm{h} / \mathrm{m}^{2}\right)\end{array}$ & $\begin{array}{l}V_{\mathrm{ss}} \\
\left(\mathrm{mL} / \mathrm{m}^{2}\right)\end{array}$ \\
\hline VSLI & 5,662 & 63,438 & 6.9 & $\mathrm{NA}^{\mathrm{a}}$ & 32 & 383 \\
VCR & 148 & 806 & 0.2 & 36.5 & 2,488 & 113,513 \\
\hline
\end{tabular}

For many liposome technology-enhanced drugs, particularly those that are slowly released from their liposome, the pharmacokinetic properties become similar to that of the liposome itself [25]. The initial formulation of liposomal VCR used distearoylphosphatidylcholine and cholesterol liposomes and a $\mathrm{pH}$ gradient to load the drug into the vesicles. This formulation demonstrated a longer circulation time, enhanced tumor delivery and antitumor activity and decreased toxicity compared to the standard formulation of VCR [29-31]. Subsequent development of liposomal formulations for VCR to optimize its pharmacokinetic properties, such as increased circulation time and enhanced delivery of the drug to target tissues, led to the identification and development of sphingomyelin/cholesterol (SM/ Chol) liposomes [32-34]. These SM/Chol liposomes offer the advantage of improved drug loading, retention and release, longer plasma circulation time and enhanced target-tissue accumulation without the technical challenges, and manufacturing expense, of surface-modified liposome technologies, for example, liposomes using Polyethylene Glycol (PEG) polymers.

\section{VSLI overview}

VSLI, Marqibo ${ }^{\circledR}$, is a proprietary sphingomyelin- and cholesterol-based nanoparticle formulation of VCR that was designed to overcome the dosing and pharmacokinetic limitations of standard VCR. As described above, prolonged exposure of cells to VCR enhances its in vitro cytotoxicity due to the fact that at longer exposure times a greater proportion of the cells will have passed through mitosis, where VCR exerts its cytotoxic effects [35-37]. The liposomal carrier component of VSLI, composed of sphingomyelin and cholesterol, was specifically designed to facilitate the loading and retention of VCR, to prolong the circulation time of encapsulated VCR, to increase extravasation into tumors and to slowly release the drug in the tumor interstitium $[38,39]$. These characteristics result in high levels of encapsulated drug in target tissues and a long duration of exposure of tumor cells to therapeutic drug concentrations as VCR is slowly released from the liposomes, leading to enhanced activity.

\section{VSLI nonclinical pharmacokinetics}

VSLI has a long circulation time and remains in the plasma instead of being rapidly and widely distributed in tissues like unencapsulated VCR [40-42]. The clearance of liposomes is largely a function of uptake by the mononuclear phagocytic system (MPS) which is influenced by the lipid composition, size of the nanoparticle and the extent of protein binding, or opsonization, by serum proteins [25]. The SM/Chol lipid composition and the $\sim 100 \mathrm{~nm}$ mean particle size of the VSLI liposome contribute to low protein binding that result in a longer circulation time for the nanoparticle [38, 43, 44]. In vitro protein binding assays demonstrated negligible levels (limit of detection $4.5 \mu \mathrm{g}$ protein/mg lipid) of bovine or human plasma proteins adsorbed to VSLI which was consistent with the biophysical properties of the SM/Chol liposome, that is, uncharged and tight lipid packing [41, 44] (unpublished data, Talon Therapeutics). Approximately $18-39 \%$ of encapsulated VCR was released at $24 \mathrm{~h}$ at $37{ }^{\circ} \mathrm{C}$ in an in vitro assay using human plasma. These characteristics of the liposome facilitate VSLI accumulation in tumors and tissues of the MPS due to the larger microvascular fenestrations in those tissues [40]. Subsequently, the nanoparticles slowly release the VCR in those tissues with an in vivo half-life of approximately $24 \mathrm{~h}$.

The pharmacokinetic profile of VSLI was established in mice, rats and dogs. The pharmacokinetic properties of VSLI are consistent across species with VSLI showing substantially lower total VCR clearance and volume of distribution $\left(\mathrm{V}_{\mathrm{ss}}\right)$ and correspondingly greater area under 
the curve (AUC) than VCR (Table 2). These data show in all three species that, compared to VCR, VSLI is not rapidly distributed to tissues in the first few minutes after administration and that it remains in the systemic circulation and subsequently distributes into MPS tissues and tissues with fenestrated vasculature (e.g., bone marrow, lymph nodes, spleen and tumors). Linear relationships between VSLI dose and total VCR AUC and $\mathrm{C}_{\max }$ (maximum concentration) were observed after single doses in rats over the dose range of $1.0-3.0 \mathrm{mg} / \mathrm{m}^{2}$ and in dogs over the range of $0.5-1.1 \mathrm{mg} / \mathrm{m}^{2}$ (not shown). Figure 1 and Table 1 illustrate the pharmacokinetic profile and calculated parameters of VSLI in rats following an IV dose. Following a brief initial decline, the reduction in total VCR concentration was minimal, suggesting a delay phase. The extensive early rapid distribution phase seen with VCR does not occur with VSLI. Total (encapsulated + free) VCR concentration declined monoexponentially. Notably, $\mathrm{V}_{\text {ss }}$ for total VCR after VSLI injection was close to plasma volume, indicating VSLI is confined within the plasma compartment for a longer period of time compared to VCR, and subsequently circulates repeatedly through target tissues and then accumulates in tissues with fenestrated vasculature, in particular, tumors and tissues of the MPS as described above. The disposition kinetics of the lipid component of VSLI was highly correlated with those for total VCR, indicating that the VCR is retained in the liposome and that the pharmacokinetics of VCR after VSLI administration is governed by the pharmacokinetics of the liposomes [40].

The pharmacokinetic profile in most dogs also showed an initial delay phase followed by a slow decline in total VCR levels with a prolonged half-life (Fig. 2). However, some dogs $(17 \%)$ showed an early rapid reduction followed by a slow decline in total plasma VCR that suggested a bi-exponential profile. Repeated doses of VSLI at 2 week intervals revealed that dogs retained their individual characteristics, that is, they continued to exhibit their mono or bi-exponential profile for the duration of the study. Analysis of the VCR in plasma demonstrated that $>90 \%$ of total VCR remained encapsulated so that the drug was not rapidly released in the systemic circulation. Thus, the difference in plasma pharmacokinetic profile was not due to release of the drug from the liposome and may represent differences in the capacity of individual animal MPS.

The extent of VCR metabolism and the metabolic profiles of VCR in rat urine and bile were similar for VSLI and VCR, indicating bioavailable VCR was metabolized similarly for both formulations. Radio-labeled mass-balance studies in rats showed that approximately $90 \%$ of the administered dose of VSLI was recovered in the urine and feces over $72 \mathrm{~h}$ post-dose, a delay of 12-48 h compared to the standard VCR formulation. This is consistent with prolonged circulation of VSLI as well as the prolonged retention of VCR within the liposomes in vivo. From either

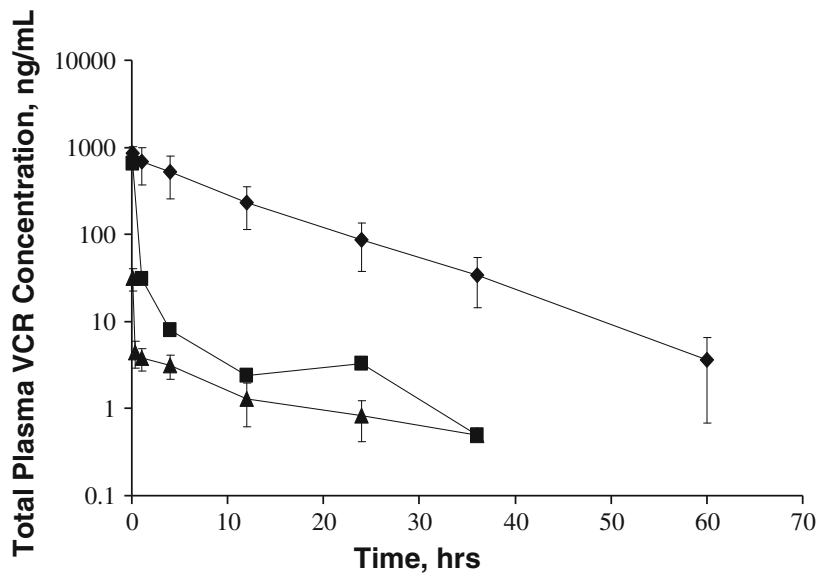

Fig. 2 Plasma vincristine concentration following administration of $0.8 \mathrm{mg} / \mathrm{m}^{2} \mathrm{VCR}$ or VSLI to dogs. Vincristine drug concentrations were measured in plasma from dogs at the indicated timepoints postdose of VSLI or vincristine. Symbols indicate the following: VSLI Monoexponential ( $N=12$, closed diamond), VSLI Bi-exponential $(N=2$, filled square $), \operatorname{VCR}(N=14$, filled triangle $)$

Table 2 Cross-species comparison of pharmacokinetic parameters

\begin{tabular}{|c|c|c|c|c|c|c|c|}
\hline & Dose $\left(\mathrm{mg} / \mathrm{m}^{2}\right)$ & $C_{\max }(\mathrm{ng} / \mathrm{mL})$ & $\mathrm{AUC}_{\mathrm{inf}}(\mathrm{ng} \cdot \mathrm{h} / \mathrm{mL})$ & $t_{1 / 2 \lambda 1}(\mathrm{~h})$ & $t_{1 / 2 \lambda z}(\mathrm{~h})$ & $\mathrm{Cl}\left(\mathrm{mL} / \mathrm{h} / \mathrm{m}^{2}\right)$ & $V_{\mathrm{ss}}\left(\mathrm{mL} / \mathrm{m}^{2}\right)$ \\
\hline \multicolumn{8}{|l|}{ Mouse $^{a}$} \\
\hline VCR & 6 & 1,470 & 11,100 & 0.19 & 24.8 & 494 & 17,214 \\
\hline VSLI & 6 & 22,600 & 351,100 & & 10.8 & 16 & 242 \\
\hline \multicolumn{8}{|l|}{ Rat } \\
\hline VCR & 2 & 148 & 806 & 0.2 & 36.5 & 2,488 & 113,513 \\
\hline VSLI & & 6,271 & 89,910 & & 6.0 & 23 & 244 \\
\hline \multicolumn{8}{|l|}{ Dog } \\
\hline VCR & 0.8 & 31 & 62 & 0.2 & 8.5 & 15,032 & 132,453 \\
\hline VSLI & 0.8 & 656 & 543 & 0.2 & 10.6 & 1,474 & 5,436 \\
\hline
\end{tabular}

${ }^{a}$ Determined from blood 
formulation, less than 10-20\% of the total radioactivity in the bile and urine was present as metabolites (Talon Therapeutics, data on file and Castle et al. 1976, Castle and Mead 1978) [45, 46]. The major route of excretion of radioactivity in VSLI-treated rats was biliary since the majority of radioactivity (75\%) was recovered in the feces. The maximum fecal excretion occurred between 24 and $72 \mathrm{~h}$, whereas the maximum urinary excretion occurred between 0 and $12 \mathrm{~h}$. Combined, these data demonstrate retention of the encapsulated drug in the liposomes and slow release of the VCR in the target tissues.

The comparative tissue distribution of total VCR following a single IV bolus injection of either VSLI or VCR was assessed in rats and mice. Following administration of VSLI, the maximum plasma concentration $\left(C_{\max }\right)$ of VCR in most tissues was between 4 and $24 \mathrm{~h}$ with the majority of tissues peaking around $16 \mathrm{~h}$. For most tissues from VSLI-treated animals, tissue to plasma concentration ratios increased over time and peaked at $72 \mathrm{~h}$ after VSLI injection, indicating progressive accumulation of radio-labeled drug from plasma into the tissues [42, 47]. The tissue distribution of total VCR was slower following administration of VSLI than after VCR, and more extensive accumulation was observed in tissues of the MPS such as the spleen, liver, lymph nodes and bone marrow (Fig. 3). The rank order of tissues based on $C_{\max }$ demonstrated that total VCR concentrations in MPS tissues and in ovaries were substantially higher than in other organs or tissues. The lowest radioactivity levels were observed in brain, spinal cord, nerves and muscle. Higher exposures, as measured by $\mathrm{AUC}_{\mathrm{inf}}$, of VCR were observed in spleen (12 fold), lymph nodes (tenfold), liver (fourfold) and bone marrow (twofold) following a radio-labeled dose of VSLI compared to VCR (Table 3). Thus, preferential accumulation of the liposomes and subsequent slow release of VCR in target tissues important in hematologic malignancies following administration of VSLI results in higher and prolonged tissue drug levels providing superior drug delivery to those tissues than the same dose of standard formulation of VCR.

The extravasation kinetics and preferential accumulation of VSLI in tumors was further investigated using intra-vital microscopy imaging in mice implanted with LX-1 cells, a xenograft model of human small-cell carcinoma [48]. Significantly faster extravasation occurred in tumor vessels than in nontumor tissues after a single dose of fluorescently labeled VSLI liposomes. The interstitial amounts of drug were approximately 70-fold higher in tumor tissues compared to nontumor tissues at $1 \mathrm{~h}$ and remained higher at 48 h. Combined, these distribution data are consistent with VSLI exiting the systemic circulation, accumulating at the site of tumors where they act as a reservoir for the release of localized VCR to enhance the antitumor activity.
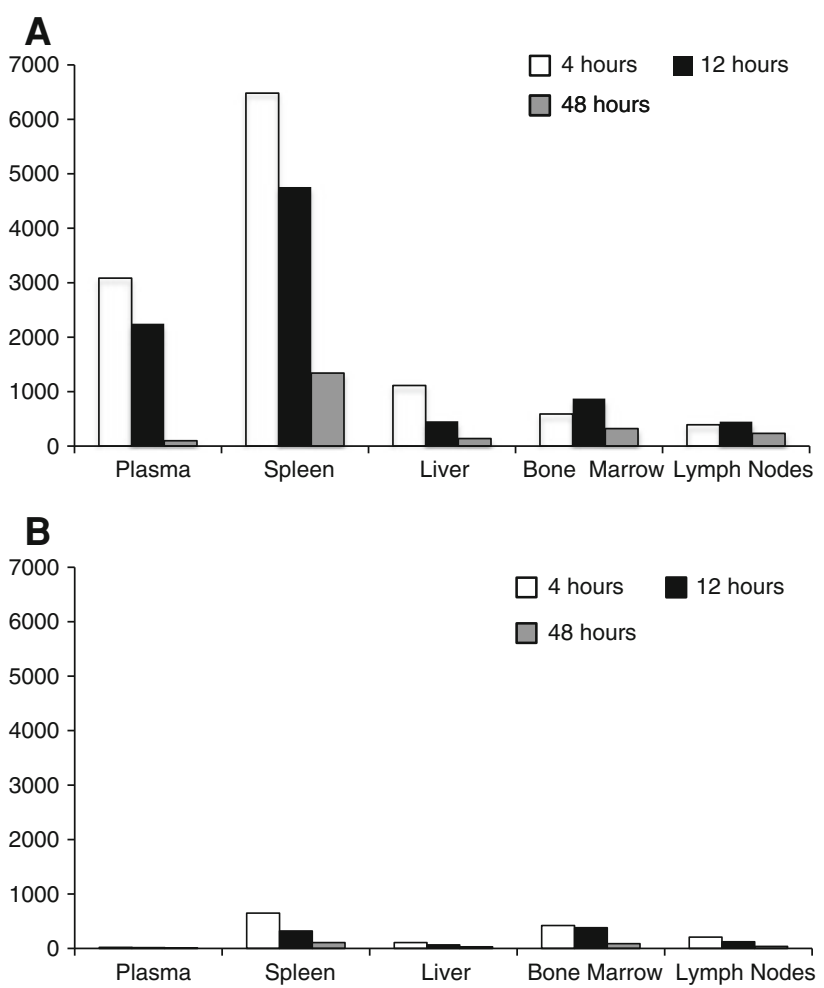

Fig. 3 Tissue total vincristine concentration following administration of VSLI (a) or VCR (b) to rats. Rats were administered a single bolus dose of $2.0 \mathrm{mg} / \mathrm{m}^{2}$ of either $\left[{ }^{3} \mathrm{H}\right]$ Vincristine or VSLI that had $\left[{ }^{3} \mathrm{H}\right]$ Vincristine encapsulated into the liposome. Tissue drug levels were measured up to $72 \mathrm{~h}$ post-dose by liquid scintillation counting of tissue samples. The bars represent samples taken at the following times: $4 \mathrm{~h}$ (open bars), $12 \mathrm{~h}$ (black bars), $24 \mathrm{~h}$ (gray bars)

Table 3 Comparison of tissue exposure to vincristine following administration of either VSLI or VCR

\begin{tabular}{lrrrr}
\hline & \multicolumn{4}{l}{$\mathrm{AUC}_{\text {inf }}, \mathrm{ng}$ eq· h/g } \\
\cline { 2 - 5 } & Spleen & Liver & $\begin{array}{l}\text { Lymph } \\
\text { node }\end{array}$ & $\begin{array}{l}\text { Bone } \\
\text { marrow }\end{array}$ \\
\hline VSLI & 381,154 & 28,202 & 66,333 & 40,936 \\
VCR & 30,765 & 6,496 & 6,420 & 17,767 \\
Ratio VSLI/VCR & 12.4 & 4.3 & 10.3 & 2.3 \\
\hline
\end{tabular}

\section{VSLI nonclinical pharmacodynamics}

The prolonged plasma circulation time and increased VCR penetration and concentration in tissues (i.e., passive targeting) of VSLI translated into enhanced antileukemia activity compared to standard VCR without additional toxicity (i.e., widens the therapeutic index). Examples of this are shown in Fig. 4. Mice bearing Namwala xenograft tumors treated with VSLI showed better tumor growth suppression at $1.0,1.5$ and $2.5 \mathrm{mg} / \mathrm{kg}$ compared to animals treated with $0.5,1.0$ or $1.5 \mathrm{mg} / \mathrm{kg}$ VCR (Fig. 4a). Tumor 
growth suppression was dose dependent for both agents; the maximum tolerated dose for VSLI was $2.5 \mathrm{mg} / \mathrm{kg}$ versus $1.5 \mathrm{mg} / \mathrm{kg}$ for VCR. The antitumor activity of VSLI was greater at each dose level with maximal activity at the MTD of $2.5 \mathrm{mg} / \mathrm{kg}$, a dose unachievable with standard formulation VCR. Similarly, in the LX-1 human small-cell lung carcinoma model, VSLI demonstrated greater antitumor activity than an equivalent dose of VCR at $1.0 \mathrm{mg} / \mathrm{kg}$ administered q7d $\times 3$ (Fig. 4b) [48].

The superior antitumor activity of VSLI compared to that of VCR was further demonstrated in a variety of human tumor xenograft and murine syngeneic models representing several cancer types. Table 4 provides a summary of studies conducted using either a single administration or a multidose regimen. Overall, in 18 animal tumor models representing 11 different cancer indications, VSLI was more active than VCR in 11 tumor models representing 8 cancer
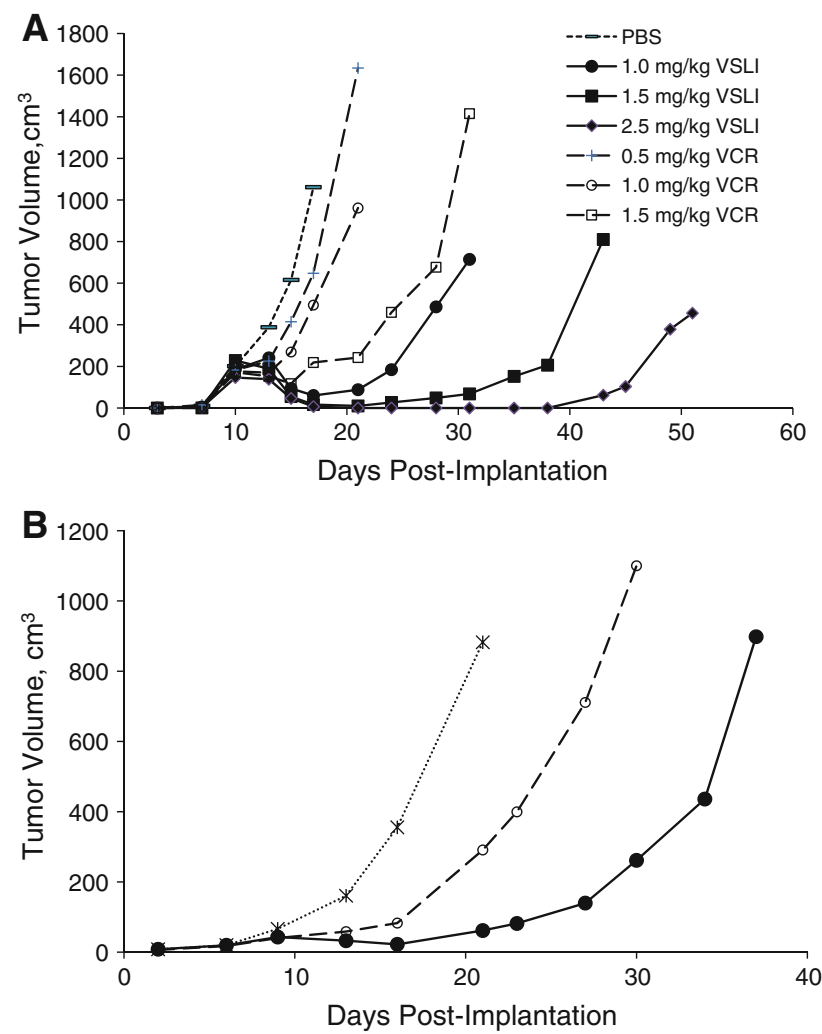

Fig. 4 VSLI and VCR antitumor activity in Namawala (a) and LX-1 (b) tumor bearing mice. Namawala (human lymphoma model) or LX1 (human SCLC model) tumor cells were implanted subcutaneously into SCID mice. Mice received vehicle (dotted line), VCR (dashed lines), or VSLI (solid lines) on days 11, 18 and 25 post-implantation. Data represent mean $\pm \mathrm{SD}, N=5-10$. The symbols indicate the following treatments: Vehicle-treated control (-), vincristine $0.5 \mathrm{mg} /$ $\mathrm{kg}(+), 1.0 \mathrm{mg} / \mathrm{kg}$ (open circle), $1.5 \mathrm{mg} / \mathrm{kg}$ (open square); VSLI $1.0 \mathrm{mg} / \mathrm{kg}$ (filled circle), $1.5 \mathrm{mg} / \mathrm{kg}$ (filled square), $2.5 \mathrm{mg} / \mathrm{kg}$ (filled diamond) indications (Table 4). Improved activity of VSLI over VCR was observed using a variety of dosing schedules and routes of tumor implantation. In all cases, VSLI antitumor activity was equivalent to or exceeded that of the same dose level of VCR; in no case was VSLI activity less than that seen at an equivalent dose level of VCR. The antitumor activity of VSLI was dose dependent in 13/18 of the tumor models evaluated (Table 4). Three models were not sensitive to either VSLI or VCR (B16/BL6 melanoma, NCI-H460 NSCLC, and HT29 colon carcinoma) while one (SR lymphoma) was very sensitive to both VSLI and VCR. Further, as measured by changes in body weight or mortality, VSLI was tolerated at higher dose levels than VCR. Combined, these nonclinical data demonstrate that VSLI has potent antitumor activity which exceeds that of conventional VCR.

Data from Leonetti et al. [49] demonstrated that VSLI is also effective in three drug-resistant tumor models that over-express $P$-glycoprotein. When treated with standard VCR, M14 melanoma, MCF-7 breast carcinoma and LoVo colon carcinoma cells showed growth delay, whereas drugresistant variants of each of those cell lines were resistant to growth inhibition by standard VCR. Xenograft tumors grown in mice from each of those cell lines were sensitive to standard VCR, whereas their resistant variants showed no delay in tumor growth. In contrast, tumors from both the parental cell lines and the drug-resistant variants were sensitive to VSLI and resulted in significant tumor growth delay. Immunohistochemical analysis of VSLI-treated tumors further demonstrated massive necrosis and apoptosis. These data suggest that VSLI may be effective in drug-resistant tumors that express increased levels of $P$-glycoprotein.

\section{VSLI clinical experience}

The pharmacokinetics of VSLI in humans is similar to that observed in nonclinical species. Specifically, VSLI is a long circulating, slow-release nanoparticle formulation of VCR that remains within the plasma compartment for a prolonged period of time compared to standard VCR (Fig. 5; Table 4). Due to the slow release of VCR from the liposome, the plasma concentration profile of total VCR represents that of the encapsulated drug. Unlike the very rapid distribution phase observed with standard VCR, a delay of $3-12 \mathrm{~h}$ in VCR clearance from plasma is observed following VSLI administration, resulting in total VCR levels that remain relatively constant before declining with time. This delay phase contributes significantly to the plasma AUC following VSLI administration. Subsequent to this delay phase, a wide variance in profiles is observed, ranging from apparent monoexponential 
Table 4 Summary of VSLI versus VCR antitumor activity in 18 human tumor xenograft models

\begin{tabular}{|c|c|c|c|c|c|}
\hline Tissue origin & $\begin{array}{l}\text { Tumor } \\
\text { model }^{\text {a }}\end{array}$ & Schedule $^{b}$ & Sensitivity to VCR & $\begin{array}{l}\text { Dose-dependent } \\
\text { antitumor activity }\end{array}$ & $\begin{array}{l}\text { Relative antitumor } \\
\text { activity }\end{array}$ \\
\hline Leukemia & P388 ${ }^{\mathrm{c}}$ (IP) & Single & Moderate & VSLI & $\mathrm{VSLI}>\mathrm{VCR}^{*}$ \\
\hline Lymphoma & Namalwa & $\mathrm{q} 7 \mathrm{~d} \times 2, \mathrm{q} 7 \mathrm{~d} \times 3$ & Moderate & VSLI, VCR & $\mathrm{VSLI}>\mathrm{VCR}^{*}$ \\
\hline Lymphoma & $\mathrm{RL}$ & $\mathrm{q} 7 \mathrm{~d} \times 3$ & High & VSLI, VCR & VSLI > VCR \\
\hline Lymphoma & DoHH2 & $\mathrm{q} 7 \mathrm{~d} \times 3$ & High & VSLI, VCR & $\mathrm{VSLI}=\mathrm{VCR}$ \\
\hline Lymphoma & SR & $\mathrm{q} 7 \mathrm{~d} \times 2$ & High & None & Unable to assess \\
\hline SCLC & LX-1 & Single & Weak & VSLI & VSLI > VCR \\
\hline SCLC & LX-1 & $\mathrm{q} 7 \mathrm{~d} \times 3$ & Moderate & NA & $\mathrm{VSLI}>\mathrm{VCR}^{*}$ \\
\hline SCLC & NCI-H69 & Single & High & VSLI, VCR & $\mathrm{VSLI}=\mathrm{VCR}$ \\
\hline SCLC & DMS273 & Single & Moderate & VSLI, VCR & $\mathrm{VSLI}=\mathrm{VCR}$ \\
\hline Breast carcinoma & MX-1 & Single & Moderate & VSLI, VCR & VSLI > VCR \\
\hline Breast carcinoma & MX-1 & $\mathrm{q} 21 \mathrm{~d} \times 2, \mathrm{q} 21 \mathrm{~d} \times 3$ & High & VSLI, VCR & $\mathrm{VSLI}>\mathrm{VCR}^{*}$ \\
\hline Breast carcinoma & MX-1 & $\mathrm{q} 7 \mathrm{~d} \times 3$ & High & VSLI, VCR & VSLI > VCR \\
\hline Breast carcinoma & MX-1 & $\mathrm{q} 7 \mathrm{~d} \times 3$ & High & VSLI, VCR & VSLI > VCR \\
\hline Renal carcinoma & RXF393 & Single & Weak & VSLI & VSLI $>$ VCR $*$ \\
\hline Prostate carcinoma & PC-3 & Single & Moderate & VSLI & VSLI > VCR \\
\hline Prostate carcinoma & PC-3 & $\mathrm{q} 7 \mathrm{~d} \times 3$ & High & VSLI, VCR & $\mathrm{VSLI}=\mathrm{VCR}$ \\
\hline Prostate carcinoma & PC-3 (OT) & $\mathrm{q} 7 \mathrm{~d} \times 3$ & Moderate & None & $\mathrm{VSLI} \geq \mathrm{VCR}$ \\
\hline Kaposi's sarcoma & My1 & $\mathrm{q} 7 \mathrm{~d} \times 3$ & Weak & VSLI, VCR & $\mathrm{VSLI} \geq \mathrm{VCR}$ \\
\hline Melanoma & $\mathrm{B} 16 / \mathrm{BL6}^{\mathrm{c}}(\mathrm{IV})$ & Single & Not sensitive & None & Unable to assess \\
\hline Melanoma & $\mathrm{B} 16 / \mathrm{BL}^{\mathrm{c}}$ & $\mathrm{q} 7 \mathrm{~d} \times 3$ & Not sensitive & None & Unable to assess \\
\hline NSCLC & NCI-H460 & Single & Not sensitive & None & Unable to assess \\
\hline Colon carcinoma & HT29 & Single & Not sensitive & None & Unable to assess \\
\hline Multiple myeloma & LAGк-1A & $\mathrm{q} 7 \mathrm{~d} \times 3$ & Moderate & VSLI & VSLI > VCR \\
\hline Multiple myeloma & LAGк-1B & $\mathrm{q} 7 \mathrm{~d} \times 3$ & Not sensitive & VSLI & VSLI > VCR \\
\hline
\end{tabular}

$I V$ intravenous, IP intraperitoneal, NA not applicable (only one dose tested), OT orthotopic, SCLC small-cell lung cancer

${ }^{\text {a }}$ Tumors were human xenograft models implanted subcutaneously, unless specified

${ }^{b}$ Repeat-dose schedules were once a week for 2 or 3 cycles $(q 7 d \times 2$ or $q 7 d \times 3)$ or every 3 weeks for 2 or 3 cycles $(q 21 d \times 2$ or q21d $\times 3)$. ${ }^{\mathrm{c}}$ Murine tumor model

* Statistically significant difference $(p<0.05)$

declines in plasma concentrations of total VCR to a range of apparent bi-exponential profiles. This variability in pharmacokinetic profile represents the clearance of the liposomes from the plasma and the capacity of the MPS system to mediate that clearance. Importantly, no differences in tolerability were seen between subjects with monoexponential and bi-exponential profiles. And gender, age, BSA, or cancer type did not affect $\mathrm{Cl}$ or exposure (AUC inf ) (Table 5).

VSLI has been studied in 20 clinical trials and 2 compassionate use programs. Malignancies represented in these trials include acute lymphoblastic leukemia (ALL), nonHodgkin's lymphoma (NHL), Hodgkin's lymphoma, and solid tumors such as metastatic melanoma and lung cancer. Both adults and children have been studied. As a result of these studies and the strong historical data demonstrating clinical activity of the standard VCR in hematologic cancers, VSLI is being developed in ALL and other hematologic malignancies.

ALL is a malignant disease of B- or T-lymphocytes characterized primarily by failure of proper cellular maturation and consequent aberrant cell proliferation. Malignant proliferation of lymphoblasts in the bone marrow and blood suppresses normal hematopoesis and may lead to infiltration of extramedullary sites such as the liver, spleen, thymus, meninges and gondads [50]. The disease is characterized by rapid progression and death if not successfully treated. Sequential modifications of treatment protocols have led to remarkable improvement in survival outcome in pediatric and adolescent ALL patients with survival rates exceeding $80 \%$. Despite the remarkable success in treatment of childhood and adolescent ALL, 


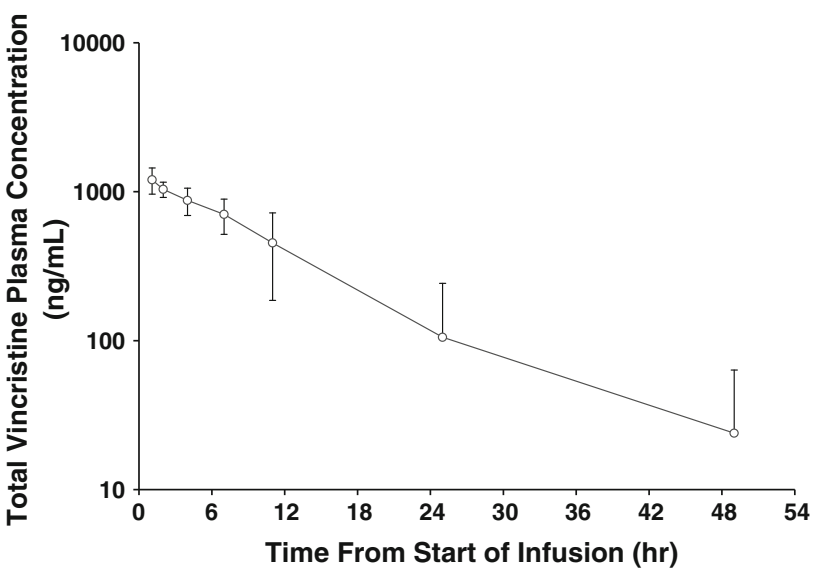

Fig. 5 Mean plasma concentration-time profile of total VCR in humans following IV administration of VSLI at $2.25 \mathrm{mg} / \mathrm{m}^{2}$. Plasma was collected from adult Ph-chromosome-negative relapsed/refractory patients, $N=12$. Total VCR concentrations were measured at the indicated times post-dose of VSLI using a validated LC/MS-MS method. The lower limit of quantitation (LLOQ) for vincristine sulfate was $1.00 \mathrm{ng} / \mathrm{mL}$. Pharmacokinetic parameters for total VCR concentrations (encapsulated and free) in plasma were calculated from the plasma concentration-time data using a noncompartmental analysis (NCA) method (WinNonlin Professional Network Edition, Version 5.2, Pharsight Corp, Palo Alto, CA, USA)

adult ALL patients are underserved by existing treatment options as reflected by the poor survival rates and extremely poor outcomes in the relapsed setting. Recent trials have shown that $65-85 \%$ of adults will achieve a complete remission; however, the duration of these responses is often short, especially in older adults [51, 52]. When relapsed, adult ALL has a poor long-term survival rate of $20-40 \%[53,54]$. Currently there is no clear standard of care or guidance for the treatment of advanced, relapsed and/or refractory ALL.

Based on the clear unmet medical need, the superiority of VSLI over standard VCR in nonclinical studies and encouraging activity in Phase 1 trials, a multi-national pivotal, Phase 2, single-arm, open-label trial (NCT00495079) of high dose $\left(2.25 \mathrm{mg} / \mathrm{m}^{2}\right)$, weekly VSLI monotherapy was conducted in heavily pre-treated adults with advanced, relapsed and refractory $\mathrm{B}$ or $\mathrm{T}$ cell lineage Philadelphia chromosome-negative (Ph-) ALL. VSLI monotherapy resulted in meaningful clinical outcomes; the $\mathrm{CR} / \mathrm{CRi}$ rate and overall response rates were $20 \%$ and $35 \%$, respectively [55]. VSLI monotherapy was effective as third-, fourth-, and fifth-line therapy and in patients refractory to other singleand multi-agent therapies. The median uncensored CR/CRi duration was 23 weeks (range 5-66 weeks), and 5 patients were long-term survivors. Importantly, 12 patients who were ineligible for immediate hematopoietic cell transplant were able to subsequently receive a transplant. The toxicity profile of high-dose VSLI was predictable, manageable and comparable to that of standard dose and formulation VCR despite the delivery of large, normally unachievable, individual and cumulative doses of VCR. These studies led to the accelerated approval of VSLI by the FDA for the treatment of adult patients with $\mathrm{Ph}$ - ALL in second or greater relapse or whose disease has progressed following two or more antileukemia therapies.

\section{Summary}

VSLI is a proprietary sphingomyelin- and cholesterolbased nanoparticle formulation of VCR that was designed to be different from and overcome the dosing and pharmacokinetic limitations of standard VCR. In nonclinical studies, VSLI: 1) increases the plasma circulation time; 2) increases tumor tissue delivery by preferential extravasation from fenestrated ("leaky") vasculature; 3) accumulates in tumor tissues; and 4) slowly releases VCR in tumor tissues instead of the systemic circulation. These unique pharmaceutical properties resulted in superior nonclinical pharmacokinetic properties in mice, rats and dogs and translated into increased efficacy in 11 murine tumor models compared to standard VCR. Clinical trials demonstrated safety, tolerability, and promising activity of VSLI in adults with advanced relapsed/refractory leukemia and lymphoma. VSLI recently received accelerated FDA approval.

Table 5 Mean plasma PK parameters of total vincristine in humans following IV administration of VSLI at $2.25 \mathrm{mg} / \mathrm{m}^{2}$

\begin{tabular}{|c|c|c|c|c|c|c|c|c|c|}
\hline & $C_{\max }(\mathrm{ng} / \mathrm{mL})$ & $T_{\max }(\mathrm{h})$ & $\mathrm{AUC}_{0-\text { last }}(\mathrm{ng} \mathrm{h} / \mathrm{mL})$ & $\operatorname{AUC}_{0-\text { inf }}(\mathrm{ng} \mathrm{h} / \mathrm{mL})$ & $t_{1 / 2}(\mathrm{~h})$ & $\mathrm{CL}(\mathrm{mL} / \mathrm{h})$ & $\mathrm{Vd}(\mathrm{mL})$ & $\mathrm{Vd}_{\mathrm{ss}}(\mathrm{mL})$ & $\mathrm{MRT}_{0-\text { inf }}(\mathrm{h})$ \\
\hline$N$ & 13 & 13 & 13 & 12 & 12 & 12 & 12 & 12 & 12 \\
\hline Mean & 1,220 & - & 13,732 & 14,566 & 7.66 & 345 & 3,569 & 2,914 & 9.63 \\
\hline SD & 229 & - & 5,666 & 6,368 & 3.18 & 177 & 1,924 & 1,219 & 4.44 \\
\hline CV \% & 18.8 & - & 41.3 & 43.7 & 41.5 & 51.2 & 53.9 & 41.8 & 46.1 \\
\hline Min & 919 & 1.08 & 6,975 & 7,036 & 4.49 & 148 & 1,540 & 1,803 & 5.38 \\
\hline Median & 1,230 & 1.25 & 13,502 & 13,680 & 6.61 & 302 & 3,254 & 2,601 & 8.43 \\
\hline Max & 1,720 & 4.17 & 24,036 & 26,074 & 12.6 & 783 & 7,754 & 6,500 & 17.7 \\
\hline
\end{tabular}


Conflict of interest Drs Silverman and Deitcher are employees of Talon Therapeutics, Inc.

Open Access This article is distributed under the terms of the Creative Commons Attribution License which permits any use, distribution, and reproduction in any medium, provided the original author(s) and the source are credited.

\section{References}

1. Johnson IS, Armstrong JG, Gorman M, Burnett JP Jr (1963) The vinca alkaloids: a new class of oncolytic agents. Cancer Res 23:1390-1427

2. Noble RL (1990) The discovery of the vinca alkaloids-chemotherapeutic agents against cancer. Biochem Cell Biol 68(12): 1344-1351

3. Noble RL, Beer CT, Cutts JH (1958) Role of chance observations in chemotherapy: vinca rosea. Ann NY Acad Sci 76(3):882-894

4. Gidding CE, Kellie SJ, Kamps WA, de Graaf SS (1999) Vincristine revisited. Crit Rev Oncol Hematol 29(3):267-287

5. van Tellingen O, Sips JH, Beijnen JH, Bult A, Nooijen WJ (1992) Pharmacology, bio-analysis and pharmacokinetics of the vinca alkaloids and semi-synthetic derivatives (review). Anticancer Res 12(5):1699-1715

6. Geyp M, Ireland CM, Pittman SM (1996) Resistance to apoptotic cell death in a drug resistant $\mathrm{T}$ cell leukaemia cell line. Leukemia 10(3):447-455

7. Harmon BV, Takano YS, Winterford CM, Potten CS (1992) Cell death induced by vincristine in the intestinal crypts of mice and in a human Burkitt's lymphoma cell line. Cell Prolif 25(6):523-536

8. Mohammad RM, Diwakaran H, Maki A, Emara MA, Pettit GR, Redman B, al-Katib A (1995) Bryostatin 1 induces apoptosis and augments inhibitory effects of vincristine in human diffuse large cell lymphoma. Leuk Res 19(9):667-673

9. Pittman SM, Strickland D, Ireland CM (1994) Polymerization of tubulin in apoptotic cells is not cell cycle dependent. Exp Cell Res 215(2):263-272

10. Takano Y, Okudaira M, Harmon BV (1993) Apoptosis induced by microtubule disrupting drugs in cultured human lymphoma cells. Inhibitory effects of phorbol ester and zinc sulphate. Pathol Res Pract 189(2):197-203

11. Degraeve N (1978) Genetic and related effects of Vinca rosea alkaloids. Mutat Res 55(1):31-42

12. Gidding CE, Meeuwsen-de Boer GJ, Koopmans P, Uges DR, Kamps WA, de Graaf SS (1999) Vincristine pharmacokinetics after repetitive dosing in children. Cancer Chemother Pharmacol 44(3):203-209

13. Suter W, Brennand J, McMillan S, Fox M (1980) Relative mutagenicity of antineoplastic drugs and other alkylating agents in V79 Chinese hamster cells, independence of cytotoxic and mutagenic responses. Mutat Res 73(1):171-181

14. Avramis IA, Kwock R, Avramis VI (2001) Taxotere and vincristine inhibit the secretion of the angiogenesis inducing vascular endothelial growth factor (VEGF) by wild-type and drug-resistant human leukemia T-cell lines. Anticancer Res 21(4):2281-2286

15. Hayot C, Farinelle S, De Decker R, Decaestecker C, Darro F, Kiss R, Van Damme M (2002) In vitro pharmacological characterizations of the anti-angiogenic and anti-tumor cell migration properties mediated by microtubule-affecting drugs, with special emphasis on the organization of the actin cytoskeleton. Int $\mathbf{J}$ Oncol 21(2):417-425

16. Baguley BC, Holdaway KM, Thomsen LL, Zhuang L, Zwi LJ (1991) Inhibition of growth of colon 38 adenocarcinoma by vinblastine and colchicine: evidence for a vascular mechanism. Eur J Cancer 27(4):482-487

17. Hill BT, Fiebig HH, Waud WR, Poupon MF, Colpaert F, Kruczynski A (1999) Superior in vivo experimental antitumour activity of vinflunine, relative to vinorelbine, in a panel of human tumour xenografts. Eur J Cancer 35(3):512-520

18. Hill SA, Lonergan SJ, Denekamp J, Chaplin DJ (1993) Vinca alkaloids: anti-vascular effects in a murine tumour. Eur J Cancer 29A(9):1320-1324

19. Holwell SE, Hill BT, Bibby MC (2001) Anti-vascular effects of vinflunine in the MAC $15 \mathrm{~A}$ transplantable adenocarcinoma model. Br J Cancer 84(2):290-295

20. Schirner M, Hoffmann J, Menrad A, Schneider MR (1998) Antiangiogenic chemotherapeutic agents: characterization in comparison to their tumor growth inhibition in human renal cell carcinoma models. Clin Cancer Res 4(5):1331-1336

21. Carbone PP, Bono V, Frei E III, Brindley CO (1963) Clinical studies with vincristine. Blood 21:640-647

22. Allen TM (1998) Liposomal drug formulations. Rationale for development and what we can expect for the future. Drugs 56(5):747-756

23. Allen TM, Cheng WW, Hare JI, Laginha KM (2006) Pharmacokinetics and pharmacodynamics of lipidic nano-particles in cancer. Anti-Cancer Agents Med Chem 6(6):513-523

24. Allen TM, Hansen CB, Lopes de Menezes DE (1995) Pharmacokinetics of long-circulating liposomes. Adv Drug Deliv Rev $16: 267-284$

25. Drummond DC, Meyer O, Hong K, Kirpotin DB, Papahadjopoulos D (1999) Optimizing liposomes for delivery of chemotherapeutic agents to solid tumors. Pharmacol Rev 51(4):691-743

26. Drummond DC, Noble CO, Hayes ME, Park JW, Kirpotin DB (2008) Pharmacokinetics and in vivo drug release rates in liposomal nanocarrier development. J Pharm Sci 97(11):4696-4740

27. Zamboni WC (2005) Liposomal, nanoparticle, and conjugated formulations of anticancer agents. Clin Cancer Res 11(23):8230 8234

28. Zamboni WC (2008) Concept and clinical evaluation of carriermediated anticancer agents. Oncologist 13(3):248-260

29. Mayer LD, Bally MB, Loughrey H, Masin D, Cullis PR (1990) Liposomal vincristine preparations which exhibit decreased drug toxicity and increased activity against murine L1210 and P388 tumors. Cancer Res 50(3):575-579

30. Mayer LD, Masin D, Nayar R, Boman NL, Bally MB (1995) Pharmacology of liposomal vincristine in mice bearing L1210 ascitic and B16/BL6 solid tumours. Br J Cancer 71(3):482-488

31. Mayer LD, Nayar R, Thies RL, Boman NL, Cullis PR, Bally MB (1993) Identification of vesicle properties that enhance the antitumour activity of liposomal vincristine against murine L1210 leukemia. Cancer Chemother Pharm 33(1):17-24

32. Boman NL, Cullis PR, Mayer LD, Bally MB, Webb MS (1998) Liposomal vincristine: the central role of drug retention in defining therapeutically optimized anticancer formulations. In: Woodle MC, Storm G (eds) Long circulating liposomes: old drugs, new therapeutics. Springer-Verlag and Landes Bioscience, Berlin, pp 29-49

33. Boman NL, Masin D, Mayer LD, Cullis PR, Bally MB (1994) Liposomal vincristine which exhibits increased drug retention and increased circulation longevity cures mice bearing P388 tumors. Cancer Res 54(11):2830-2833

34. Boman NL, Mayer LD, Cullis PR (1993) Optimization of the retention properties of vincristine in liposomal systems. Biochim Biophys Acta 1152(2):253-258

35. Burris HA 3rd, Hanauske AR, Johnson RK, Marshall MH, Kuhn JG, Hilsenbeck SG, Von Hoff DD (1992) Activity of topotecan, a new topoisomerase I inhibitor, against human tumor colonyforming units in vitro. J Nat Cancer Inst 84(23):1816-1820 
36. Georgiadis MS, Russell EK, Gazdar AF, Johnson BE (1997) Paclitaxel cytotoxicity against human lung cancer cell lines increases with prolonged exposure durations. Clin Cancer Res 3(3):449-454

37. Jackson DV Jr, Bender RA (1979) Cytotoxic thresholds of vincristine in a murine and a human leukemia cell line in vitro. Cancer Res 39(11):4346-4349

38. Johnston MJ, Semple SC, Klimuk SK, Edwards K, Eisenhardt ML, Leng EC, Karlsson G, Yanko D, Cullis PR (2006) Therapeutically optimized rates of drug release can be achieved by varying the drug-to-lipid ratio in liposomal vincristine formulations. Biochim Biophys Acta 1758(1):55-64

39. Zhigaltsev IV, Maurer N, Akhong QF, Leone R, Leng E, Wang J, Semple SC, Cullis PR (2005) Liposome-encapsulated vincristine, vinblastine and vinorelbine: a comparative study of drug loading and retention. J Control Release 104(1):103-111

40. Krishna R, Webb MS, St Onge G, Mayer LD (2001) Liposomal and nonliposomal drug pharmacokinetics after administration of liposome-encapsulated vincristine and their contribution to drug tissue distribution properties. J Pharm Exp Ther 298(3):12061212

41. Webb MS, Harasym TO, Masin D, Bally MB, Mayer LD (1995) Sphingomyelin-cholesterol liposomes significantly enhance the pharmacokinetic and therapeutic properties of vincristine in murine and human tumour models. Br J Cancer 72(4):896-904

42. Webb MS, Logan P, Kanter PM, St-Onge G, Gelmon K, Harasym T, Mayer LD, Bally MB (1998) Preclinical pharmacology, toxicology and efficacy of sphingomyelin/cholesterol liposomal vincristine for therapeutic treatment of cancer. Cancer Chemother Pharmacol 42(6):461-470

43. Johnston MJ, Semple SC, Klimuk SK, Ansell S, Maurer N, Cullis PR (2007) Characterization of the drug retention and pharmacokinetic properties of liposomal nanoparticles containing dihydrosphingomyelin. Biochim Biophys Acta 1768(5):1121-1127

44. Oja CD, Semple SC, Chonn A, Cullis PR (1996) Influence of dose on liposome clearance: critical role of blood proteins. Biochim Biophys Acta 1281(1):31-37

45. Castle MC, Margileth DA, Oliverio VT (1976) Distribution and excretion of $(3 \mathrm{H})$ vincristine in the rat and the dog. Cancer Res 36(10):3684-3689

46. Castle MC, Mead JA (1978) Investigation of the metabolic fate of tritiated vincristine in the rat by high-pressure liquid chromatography. Biochem Pharmacol 27(1):37-44
47. Kanter PM, Klaich GM, Bullard GA, King JM, Bally MB, Mayer LD (1994) Liposome encapsulated vincristine: preclinical toxicologic and pharmacologic comparison with free vincristine and empty liposomes in mice, rats and dogs. Anticancer Drugs 5(5): 579-590

48. Shan S, Flowers C, Peltz CD, Sweet H, Maurer N, Kwon EJ, Krol A, Yuan F, Dewhirst MW (2006) Preferential extravasation and accumulation of liposomal vincristine in tumor comparing to normal tissue enhances antitumor activity. Cancer Chemother Pharmacol 58(2):245-255

49. Leonetti C, Scarsella M, Semple SC, Molinari A, D'Angelo C, Stoppacciaro A, Biroccio A, Zupi G (2004) In vivo administration of liposomal vincristine sensitizes drug-resistant human solid tumors. Int J Cancer 110(5):767-774

50. Pui CH, Robison LL, Look AT (2008) Acute lymphoblastic leukaemia. Lancet 371(9617):1030-1043

51. Hoelzer D, Thiel E, Ludwig WD, Loffler H, Buchner T, Freund M, Heil G, Hiddemann W, Maschmeyer G, Volkers B et al (1993) Follow-up of the first two successive German multicentre trials for adult ALL (01/81 and 02/84). German Adult ALL Study Group. Leukemia 7(Suppl 2):S130-S134

52. Kantarjian HM, O'Brien S, Smith TL, Cortes J, Giles FJ, Beran M, Pierce S, Huh Y, Andreeff M, Koller C, Ha CS, Keating MJ, Murphy S, Freireich EJ (2000) Results of treatment with hyperCVAD, a dose-intensive regimen, in adult acute lymphocytic leukemia. J Clin Oncol 18(3):547-561

53. O'Brien S, Thomas D, Ravandi F, Faderl S, Cortes J, Borthakur G, Pierce S, Garcia-Manero G, Kantarjian HM (2008) Outcome of adults with acute lymphocytic leukemia after second salvage therapy. Cancer 113(11):3186-3191

54. Dores GM, Devesa SS, Curtis RE, Linet MS, Morton LM (2012) Acute leukemia incidence and patient survival among children and adults in the United States, 2001-2007. Blood 119(1):34-43

55. O'Brien S, Schiller G, Lister J, Damon L, Goldberg S, Aulitzky W, Ben-Yehuda D, Stock W, Coutre S, Douer D, Heffner LT, Larson M, Seiter K, Smith S, Assouline S, Kuriakose P, Maness L, Nagler A, Rowe J, Schaich M, Shpilberg O, Yee K, Schmieder G, Silverman JA, Thomas D, Deitcher SR, Kantarjian H (2012) High-dose vincristine sulfate liposome injection for advanced, relapsed, and refractory adult Philadelphia chromosome-negative acute lymphoblastic leukemia. J Clin Oncol [Epub ahead of print] 